\title{
Caracterização fenotípica e diversidade genética de caprinos: revisão
}

\section{Bárbara de Cássia Ribeiro Vieira ${ }^{1}$, Marcela Brite Alfaiate ${ }^{2}$, Aparecida de Fátima Madella- Oliveira $^{3}$, Célia Raquel Quirino ${ }^{4 *}$, Mayk Henrique Souza ${ }^{5}$, Ana Paula Guedes Oliveira ${ }^{1}$, Renata Cogo Clipes ${ }^{4}$, Maurício Alves do Amaral ${ }^{4}$}

\author{
${ }^{l}$ Alunas do curso de Pós Graduação Stricto Sensu em Medicina Veterinária da Universidade Federal do \\ Espírito Santo, Alegre, ES. \\ ${ }^{2}$ Aluna do curso de Licenciatura em Ciências Biológicas do Instituto Federal do Espírito Santo - Campus de \\ Alegre, ES. \\ ${ }^{3}$ Professores do Instituto Federal do Espírito Santo - Campus de Alegre, ES. \\ ${ }^{4}$ Laboratório de Reprodução e Melhoramento Genético Animal do Centro Ciências e Tecnologias \\ Agropecuárias, Universidade Estadual do Norte Fluminense, Campos dos Goytacazes, RJ \\ ${ }^{5}$ Tecnólogo em Cafeicultura do Instituto Federal do Espírito Santo - Campus de Alegre, ES. \\ *Autorpara correspondência, E-mail: crq@uenf.br
}

\begin{abstract}
RESUMO. A pesquisa teve por objetivo realizar um estudo sobre a caracterização fenotípica e diversidade genética de caprinos. Estudos são necessários quanto à diversidade genética, uma vez que, a mesma é a base para o estabelecimento de programas de conservação e de melhoramento. Uma ferramenta eficaz para auxiliar estes estudos é a caracterização fenotípica, onde dados morfológicos podem gerar informações úteis na determinação das relações genéticas entre populações e raças.
\end{abstract}

Palavras-chave: ácido desoxirribonucleico, cabra, fenótipo.

\section{Phenotypic characterization and genetic diversity of goats: review}

\begin{abstract}
The research aimed to conduct a study on the phenotypic characterization and genetic diversity of goats. Studies are needed for genetic diversity, since the same is the basis for the establishment of conservation and breeding programs. An effective tool in assisting these studies is the phenotypic characterization, where morphological data can yield useful information in determining the genetic relationships among populations and races.
\end{abstract}

Keywords: deoxyribonucleic acid, goat phenotype.

\section{Introdução}

Os primeiros caprinos que chegaram ao Brasil foram trazidos pelos colonizadores portugueses (Barros et al., 2011). Esses animais apresentam uma estimativa de 14 milhões de indivíduos (MAPA, 2013), concentrando-se na região Nordeste, sobretudo no semi-árido(Machado et al., 2000). Todavia, a introdução de raças exóticas no país está provocando modificações na diversidade genética caprina nacional.De acordo com Gutiérrez et al. (2003), o conhecimento da diversidade genética é a base para o estabelecimento de programas de conservação e seleção, sendo preciso realizar estudos e definir estratégias de conservação para as raças nativas caprinas, uma vez que a diversidade genética representa um importante recurso.
O estudo da caracterização fenotípica é a primeira medida para o estudo das raças, pois abrange desde aspectos relacionados ao animal até o ambiente no qual ele está inserido. Desta forma, tal estudo apresenta-se como principal ferramenta para compreensão das variadas formas de desenvolvimento e criação das raças, bem como as características que as diferenciam, sua importância cultural, social e econômica para seus criadores (Nascimento, 2010).

Apesar dos grandes avanços da genética molecular, a caracterização fenotípica ainda é considerada a base para os programas de conservação e melhoramento, bem como a primeira forma de aproximação do padrão racial (Nascimento, 2010). Objetivou-se realizar um 
estudo sobre a caracterização fenotípica e diversidade genética de caprinos.

\section{Introdução do caprino no Brasil}

O rebanho de caprinos do Brasil apresenta aproximadamente 14 milhões de animais (MAPA, 2013), localizados na região Nordeste, concentração que é favorecida por razões socioeconômicas e vantagens climáticas. Constam na composição deste rebanho, animais de raças nativas (Moxotó e Canindé), raças exóticas (Saanen, Anglonubiana, Alpina, Toggemburg e Boer) além de ecótipos regionais (Marota, Repartida, Azul e Nambi). Contudo, a maioria dos caprinos é considerada SRD (semraça-definida) e/ou crioulo, produto de cruzamento indiscriminado entre animais de grupos nativos com as raças exóticas, e/ou deles entre si, respectivamente (Machado et al., 2000).

No Brasil, a chegada dos animais de fazenda teve início em São Vicente (SP), seguido de Recife (PE) e Salvador (BA). Os primeiros caprinos introduzidos são datados entre os séculos XVI e XVII. Nesta época, ainda não existia conceito de raça. Porém, tais animais já apresentavam características fenotípicas peculiares. Raças modernas só chegaram ao Brasil no século XIX de acordo comMachado (1995).

A maioria dos caprinos é criada em sistemasemi-extensivo e extensivo para produção de leite, carne e pele (Menezes et al., 2006). Contudo, a introdução significativa de raças exóticas no país tem provocado modificações consideráveis na diversidade genética caprina nordestina do Brasil.

Segundo Costa (2010) a espécie Capra hircus(caprino) está presente em quase todo o mundo, a qual demonstra particularidades resultantes de anos de seleção, originando caprinos com potencial para exploração sustentável em diversos ambientes, além do aspecto econômico e genético, assumindo um papel preponderante no plano social, representando a cultura e história de um povo.

A adaptação eficiente destes animais às condições edafoclimáticas da região, além da baixa necessidade de recursos iniciais, torna a criação de ruminantes deste porte uma alternativa viável para a geração de renda, promovendo maior segurança alimentar para as famílias dependentes dessa atividade, principalmente aquelas alocadas nas áreas mais secas (Nogueira et al., 2008). Segundo Quadros (2008) a adaptabilidade dos caprinos às condições adversas faz com que eles apresentem maior eficiência produtiva em relação a qualquer outro ruminante doméstico, inclusive ovino, bovino e bubalino, uma vez que estão presentes em regiões onde o desenvolvimento de outras espécies é inviável.

\section{Caracterizaçãofenotípica}

Os sistemas de seleção clássica dependem da avaliação e mensuração das características fenotípicas, havendo necessidade de esperar o desenvolvimento natural do animal avaliado, para a realização das mensurações nos momentos em que os fenótipos se manifestam naturalmente. Essa abordagem possui um forte componente de subjetividade uma vez que está sujeita a erros humanos e estatísticos, apesar de ser a única base técnica disponível para o melhoramento genético até o presente (Garcia \& Porto Neto, 2006).

Segundo Rodero \& Herrera (2000), estes estudos devem visar a caracterização, identificação e a diferenciação das populações revelando a origem e a história das raças, seu senso e distribuição geográfica, qualidades e aptidões, caracteres etnológicos, descrição fenotípica, estudos morfoestruturais e o uso de polimorfismos entre as raças. A utilização de caracteres étnicos permite caracterizar ou classificar indivíduos e raças de uma população. Tais caracteres podem ser definidos como uma particularidade individual em destaque, que, em maior ou menor grau de variação, determina o tipo de raça ou tipo étnico a qual pertence (Rodero et al., 1992). Assim, uma vez definidos os valores referentes a cada caráter, utilizam-se ferramentas estatísticas para comparar a variabilidade existente, entre indivíduos ou entre populações e, averiguar a possibilidade de pertencer ou não a uma raça ou grupo genético(Zepeda et al., 2002).

Estudos utilizaram dados qualitativos e/ou quantitativos de caracteres morfológicos e étnicos para analisar as relações existentes entre populações de caprinos como os desenvolvidos 
por Lauvergne et al. (1987)e Zepeda et al. (2002) que também observaram características fenotípicas visíveis e consideram o seu modo de herança. O desconhecimento do potencial de animais nativos tem limitado sua inclusão em sistemas de produção, ao mesmo tempo, dificultado também ações de conservação, razão pela qual, a caracterização fenotípica tem importância em programas de conservação (Chacon et al., 2008). A caracterização fenotípica deve ser realizada com finalidade de discriminar populações, segundo Tixier-Boichard et al. (2008).

Alguns marcadores fenotípicos estão associados à resistência à infecção e podem ser utilizados como parâmetros em programas de seleção (Bricarello et al., 2007, Coutinho, 2012, Neves, 2010). Como marcadores fenotípicos para identificar os animais geneticamente resistentes a parasitoses, destacam-se: contagem de ovos nas fezes, volume globular (Sotomaior et al., 2007), número de mastócitos(Wildblood et al., 2005), eosinófilos circulantes (Souza et al., 2006) e o método Famacha(Burke et al., 2007). Conforme Coutinho (2012), a correlação entre os parâmetros fenotípicos são ferramentas auxiliadoras para a seleção de animais com maior resistência as infecções gastrintestinais causadas por nematoides.

A caracterização fenotípica, segundo FAO (2013), consiste em avaliar quantitativamente a diversidade existente nos recursos genéticos animais (RGAn). Uma raça deve ser entendida e documentada sistematicamente sobre as suas características observáveis, ambiente de produção, distribuição geográfica e como ela deve ser mantida, bem como sua utilidade, status atual e valor em seu país. Apesar de sua importância, poucos são os trabalhos de caracterização fenotípica realizados no país.

De acordo com Costa (2010), os marcadores fenotípicos podem ser divididos em dois tipos: os marcadores morfológicos que levam em consideração a forma dos caracteres como os são, assim como usados por Mendel e os marcadores biométricos, caracterizados por serem mensurados e de herança quantitativa. Apesar de estes marcadores serem influenciados pelo meio, estes têm demonstrado bons resultados de caracterização e diversidade genética, uma vez que estudos morfológicos podem gerar informações muito úteis na determinação das relações genéticas entre populações ou raças, permitindo o agrupamento dos animais de uma mesma espécie em raças distintas (Jordana \& Parés, 1999).

Alguns estudos abordando marcadores fenotípicos em caprinos já foram realizados no Brasil, bem como na região sudeste do país, como por Madella-Oliveira \& Quirino (2012), as quais caracterizaram morfologicamente as cabras de regiões montanhosas no Estado do Espírito Santo por meio de coloração e comprimento de pelagem, comprimento de orelha, presença ou ausência de barba e chifre. Aiura et al. (2010) também estudou caprinos nesta região, mais precisamente nos Estados de Minas Gerais e São Paulo. Em outros países, pesquisas abordando esses aspectos também foram realizadas, há exemplo de Zepeda et al. (2002)os quais trabalharam na Espanha.

Pesquisas abordando características morfométricas, as quais sofrem influência do meio ambiente, para caracterizar fenotipicamente os caprinos, também têm sido desenvolvidos para geração de informações em estudos de relações genéticas (Dossa et al., 2007, Sowande \& Sobola, 2008). Estudiosos caracterizaram morfometricamente os caprinos no Brasil, como, por exemplo,Menezes et al. (2007), Mello \& Schimidt (2008), Menezes et al. (2012), dentre outros.

\section{Diversidade genética}

A espécie caprina caracteriza-se por um número elevado de raças e de populações que no decorrer dos anos se desenvolveram e se adaptaram ao diversos tipos de clima e de condições geográficas, contribuindo para o estabelecimento de uma elevada variabilidade intraespecífica. Contudo, nas ultimas décadas, assiste-se a uma notável redução dessa diversidade no que diz respeito à produção animal, esse fato se deu possivelmente, pelo contínuo processo de industrialização do agronegócio e, por consequência, uma padronização nas ações de melhoramento e produção (Rubino \& Haenlein, 1997).

De acordo com Gutiérrez et al. (2003), o conhecimento da diversidade genética é a base 
para o estabelecimento de programas de conservação e seleção. Porém, poucos são os trabalhos realizados com esses animais, onde para mitigar esses problemas, faz-se o estudo da caracterização genética desses patrimônios genéticos (Menezes et al., 2006) direcionando os recursos existentes para sua conservação. A variabilidade genética total das espécies pode ser representada pela contribuição das variações intra e inter-raciais, verificando-se, portanto, a importância de se medir a variabilidade genética dos animais para sua conservação. Desta maneira, é preciso realizar estudos e definir estratégias de conservação para as raças nativas de caprinos, pois a diversidade genética representa um importante recurso.

Pesquisas já foram realizadas visando à caracterização de diversidade genética da espécie caprina em geral com base em: perfis genéticos visíveis (Lauvergne et al., 1987), estudos da proteína do leite(Ramunno et al., 2001) marcadores de microssatélites (Oliveira et al., 2007) e polimorfismo na região mitocondrial(Luikart et al., 2001). Outros autores também descreveram sobre a diversidade genética caprina, como: Egito et al. (2002), Menezes et al. (2006), Oliveira et al. (2006), Sarmento et al. (2006), Barros et al. (2011).

Para Eding \& Laval (1999) a diversidade genética pode ser definida em diversos níveis. Observando-se o fenótipo dos animais, uma grande parte da diversidade encontra-se encoberta ou oculta, devido ao fato da diversidade total ser composta por elementos geneticamente expressos e não-expressos ou neutros. A diversidade genética por definição é aquela contida nos cromossomos de cada célula. Conforme a FAO (2013), com relação à diversidade genética, o maior número de alelos deve ser preservado, o que implica num esforço de preservar a diversidade total. As pesquisas de diversidade com caprinos no Brasil ainda são restritos.

Nos últimos anos, grandes avanços têm sido feitos nas áreas de genética molecular e genética quantitativa. Vários genes e proteínas têm sido identificados e estudados, permitindo entender como eles afetam o desenvolvimento, crescimento e metabolismo de animais e plantas. Novas metodologias na genética molecular estão sendo usadas na dissecação de características quantitativas, identificando regiões no genoma que influenciam estas características (QTLs, Locus de características quantitativas) e, para posteriormente identificar os genes presentes nestas regiões que estejam causando este efeito (Liu et al., 1999).

O primeiro passo para definição de uma política de conservação de uma raça é o inventário. O qual inclui o histórico da raça, levantamento populacional e localização de rebanhos. Dessa forma, o resultado do inventário revela a necessidade de conservação, onde as raças devem ser categorizadas quanto ao risco de extinção elaborando-se um plano de ação para sua sobrevivência. $\mathrm{O}$ processo de caracterização, associado ao inventário, é uma ferramenta primordial para a decisão e direcionamento para um programa de conservação (Tixier-Boichard et al., 2008). Conforme Delgado (2002), a conservação de uma raça enquanto recurso genético in situ depende de certas prioridades, como; vulnerabilidade, aspectos genéticos e produtivos, importância estética e culturalhistórica, aspectos ecológicos, importância social e possibilidade de evolução e manutenção como raça.

O desconhecimento da variabilidade genética da espécie caprina no mundo representa um grande perigo para conservação, podendo contribuir para a extinção de raças antes mesmo de serem caracterizadas. A variabilidade genética é um parâmetro extremamente importante para conservação dos recursos genéticos. O avanço no melhoramento genético dos rebanhos somente pode ser alcançado a partir do momento que existe variabilidade genética. $\mathrm{O}$ melhoramento genético a quais as espécies domésticas têm sido submetidas visa, principalmente, selecionar, multiplicar e distribuir os animais com características favoráveis, para tornar os rebanhos mais produtivos.

A conservação vem sendo realizada por meio dos Núcleos de Conservação, mediante o armazenamento de sêmen e embriões (ex situ) e mantidos no habitat onde os animais se desenvolveram e foram submetidos à seleção natural (in situ). Dentre as etapas envolvidas no processo pode-se citar a avaliação do potencial produtivo da população, caracterização fenotípica 
e genotípica e identificação das populações em risco de extinção ou diluição genética. A conservação de recursos genéticos animais no país apresenta como objetivos monitorar, identificar, caracterizar e implantar núcleos de conservação, conservar ex situ o material genético por meio da criopreservação de embriões e sêmen, dentre outros (Egito et al., 2002). Para Barros et al. (2011) faz-se necessário perceber que os recursos genéticos de um país constituem um patrimônio biológico único.

A conservação de recursos genéticos animais tem por objetivo manter os repositórios de alelos e de combinações alélicas que possam vir a suprir necessidades do melhoramento animal, até mesmo de nichos pouco privilegiados pelos objetivos da indústria agropecuária, como genes relacionados à adaptação a condições tropicais e de baixo investimento tecnológico.

\section{Conclusão}

A caracterização fenotípica é primordial para o estudo das raças, pois abrange desde aspectos relacionados ao animal até o ambiente no qual ele está inserido. Tais estudos utilizando caracteres morfológicos podem gerar informações muito úteis na determinação das relações genéticas entre raças ou populações.

O rebanho nacional de caprinos está perdendo sua diversidade genética devido à introdução de espécies exóticas. Tal perda é de grande preocupação, uma vez que, a conservação dos recursos genéticos objetiva manterem os repositórios alélicos que possam suprir as necessidades do melhoramento animal.

\section{Referências Bibliográficas}

Aiura, A. L. O., Aiura, F. S. \& Silva, R. G. 2010. Características do pelame de cabras saanen e pardo alpina criadas em ambiente tropical. Archivos de Zootecnia, 59, 609-612.

Barros, E. A., Ribeiro, M. N., Almeida, M. J. O. \& Araújo, A. M. 2011. Estrutura populacional e variabilidade genética da raça caprina Marota. Archivos de Zootecnia, 60, 543-552.

Bricarello, P. A., Zaros, L. G., Coutinho, L., Rocha, R. A., Kooyman, F. J., Baker, D. H., Lima, L. G., Pires, A. V. \& Amarante, A. F. T. 2007. Field study on nematode resistance in Nelore-breed cattle. Veterinary Parasitology, 148, 272-278.

Burke, J. M., Kaplan, R. M., Miller, J. E., Terrill, T. H., Getz, W. R., Mobini, S., Valencia, E., Williams, M. J., Williamson, L. H. \& Vatta, A. F. 2007. Accuracy of the FAMACHA system for on-farm use by sheep and goat producers in the southeastern United States. Veterinary Parasitology, 147, 89-95.

Chacon, E., Macedo, F., McManus, C. M., Paiva, S., Velázquez, R. F. \& Pérez, P. E. 2008. Índices zoométricos de uma amostra de Cabras Crioulas Cubanas. Simpósio Brasileiro de Melhoramento Animal, 8.

Costa, M. S. 2010. Inventário e caracterização de caprinos do grupo naturalizado Gurguéia e sua relação com os principais grupos genéticos do semi-árido do estado do Piauí. Dissertação de Mestrado, Universidade Federal do Piauí.

Coutinho, R. M. A. 2012. Marcadores fenotípicos para caracterização de caprinos com diferentes níveis de resistência às endoparasitoses gastrintestinais. Animal Science. Universidade Federal do Rio Grande do Norte.

Delgado, J. V. 2002. Conservación de los recursos genéticos animales y los sistemas de explotación tradicionales dentro del Programa Iberoamericano de Ciencia y Tecnología para el Desarrollo (CYTED). Archivos de Zootecnia, 51, 3.

Dossa, L. H., Wollny, C. \& Gauly, M. 2007. Spatial variation in goat populations from Benin as revealed by multivariate analysis of morphological traits. Small Ruminant Research, 73, 150-159.

Eding, J. H. \& Laval, G. 1999. Measuring genetic uniqueness in livestock. Genebanks and the Conservation of Farm Animal Genetic Resources, 35-58.

Egito, A. A., Mariante, A. S. \& Albuquerque, M. S. M. 2002. Programa brasileiro de conservação de recursos genéticos animais. Archivos de Zootecnia, 51, 39-52.

FAO. 2013. Statistical Yearbook. Food and Agriculture Organization of the United Nations, Rome, Italy. 
Garcia, J. F. \& Porto Neto, L. P. 2006. Uso de marcadores moleculares em programas de transferência de embriões. Acta Scientiae Veterinariae, 34, 197-203.

Gutiérrez, J. P., Altarriba, J., Díaz, C., Quintanilla, R., Cañón, J. \& Piedrafita, J. 2003. Pedigree analysis of eight Spanish beef cattle breeds. Genetics Selection Evolution, 35, 43-64.

Jordana, J. \& Parés, P. M. 1999. Relaciones genéticas entre razas ibéricas de caballos utilizando caracteres morfológicos (prototipos raciales). Animal Genetic Resources Information, 26, 75-94.

Lauvergne, J. J., Renieri, C. \& Audiot, A. 1987. Estimating erosion of phenotypic variation in a French goat population. Journal of Heredity, 78, 307-314.

Liu, Q., Feng, J., Buzin, C., Wen, C., Nozari, G., Mengos, A., Nguyen, V., Liu, J., Crawford, L. \& Fujimura, F. K. 1999. Detection of virtually all mutations-SSCP (DOVAM-S): a rapid method for mutation scanning with virtually 100\% sensitivity. Biotechniques, 26, 932-945.

Luikart, G., Gielly, L., Excoffier, L., Vigne, J.D., Bouvet, J. \& Taberlet, P. 2001. Multiple maternal origins and weak phylogeographic structure in domestic goats. Proceedings of the National Academy of Sciences, 98, 59275932.

Machado, T. M. M. 1995. Le peuplement des animaux de ferme et l'élevage de la chèvre au Brésil avec une étude du polymorphisme visible de la chèvre du Ceará. Animal Science. University of Paris XI, Paris.

Machado, T. M. M., Chakir, M. \& Lauvergne, J. J. 2000. Genetic distances and taxonomic trees between goats of Ceará state (Brazil) and goats of the Mediterranean region (Europe and Africa). Genetics and Molecular Biology, 23, 121-125.

Madella-Oliveira, A. F. \& Quirino, C. R. 2012. Caracterização do rebanho de cabras semisselvagens das montanhas do sul do Esperíto Santo, Brasil. Actas Iberoamericanas de Conservación Animal, 2, 319-322.
MAPA. 2013. Instrução Normativa $n^{\circ} 62$ de 31/12/2011. Ministério da Agricultura, Pecuária e Abastecimento.

Mello, F. A. \& Schimidt, V. 2008. Caracterização biométrica de caprinos Anglo-Nubianos nascidos no Brasil, no período de 1993 a 2001. Archivos de Zootecnia, 57, 525-535.

Menezes, J. J. L., Gonçalves, H. C., Cañizares, G. I. L., Rodrigues, L., Medeiros, B. B. L., Gomes, H. F. B., Marques, R. O. \& Emerson, M. S. 2012. Ganho de peso e medidas biométricas de caprinos jovens em função do gruporacial, peso de abate e sexo. Veterinária e Zootecnia. Veterinária e Zootecnia, 19, 574583.

Menezes, J. J. L., Gonçalves, H. C., Ribeiro, M. S., Rodrigues, L., Cañizares, G. I. L., Medeiros, B. B. L. \& Giassetti, A. P. 2007. Desempenho e medidas biométricas de caprinos de diferentes grupos raciais. Revista Brasileira de Zootecnia, 36, 635-642.

Menezes, M. P. C., Martinez, A. M., Ribeiro, M. N., Pimenta Filho, E. C. \& Bermejo, J. V. D. 2006. Caracterização genética de raças caprinas nativas brasileiras utilizando-se 27 marcadores microssatélites. Revista Brasileira de Zootecnia, 35, 1336-1341.

Nascimento, R. B. 2010. Caracterização morfoestrutural e do sistema de criação da raça Moxotó em seu centro de origem com base no conhecimento local. Departamento de Zootecnia. Universidade Federal Rural de Pernambuco, Recife.

Neves, M. R. M. 2010. Utilização de marcadores fenotípicos para caracterização de ovinos mestiços Santa Inês naturalmente infectados com nematóides gastrintestinais. Departamento de Zootecnia. Universidade Estadual Vale do Acaraú, Sobral.

Nogueira, D. M., Chapaval, L., Neves, A. L. A. \& Costa, M. M. 2008. Passos para obtenção de leite de cabra com qualidade. Embrapa Semi-Árido. Comunicado Técnico.

Oliveira, J. C. V., Benício, R. C., Rocha, L. L., Ribeiro, M. N. \& Delgado, J. V. 2007. Avaliação morfoestutural de caprinos da raça Moxotó. Archivos de Zootecnia, 56, 483-488. 
Oliveira, J. C. V., Rocha, L. L., Ribeiro, M. N. \& Gomes Filho, M. A. 2006. Caracterização e perfil genético visível de caprinos Nativos no Estado de Pernambuco. Archivos de Zootecnia, 55, 63-73.

Quadros, D. G. 2008. Leite de cabra: produção e qualidade. PUBVET-Publicações em Medicina Veterinária e Zootecnia, 2, 1-5.

Ramunno, L., Longobardi, E., Pappalardo, M., Rando, A., Di Gregorio, P., Cosenza, G., Mariani, P., Pastore, N. \& Masina, P. 2001. An allele associated with a non-detectable amount of as 2 casein in goat milk. Animal Genetics, 32, 19-26.

Rodero, E. \& Herrera, M. 2000. El concepto de raza. Un enfoque epistemológico. Archivos de Zootecnia, 49, 5-16.

Rodero, E., Herrera, M. \& Gutiérrez, M. J. 1992. Morphostructural evolution of the Blanca Serrana caprine breed based on their crossing for milking aptitude. Archivos de Zootecnia, 41, 519-530.

Rubino, R. \& Haenlein, G. F. W. 1997. Goat milk production systems: sub-systems and differentiation factors. Cahiers Options Mediterraneennes.

Sarmento, J. L. R., Reis Filho, J. C., Albuquerque, L. G. d., Lopes, P. S. \& Rodrigues, M. T. 2006. Avaliação genética de caprinos da raça Alpina utilizando-se a produção de leite no dia do controle. Revista Brasileira de Zootecnia, 35, 443-451.

Sotomaior, C. S., Carli, L. M., Tangleica, L., Kaiber, B. K. \& Souza, F. P. 2007. Identificação de ovinos e caprinos resistentes e susceptíveis aos helmintos gastrintestinais. Revista Acadêmica, 5, 397-412.
Souza, C., Anjos Lopes, S. T., Batina, P. N., Cecim, M., Cunha, C. M., Carvalho Conrado, A. \& Beck, A. 2006. Estresse parasitário em cabras saanen: Avaliação hematológica e da atividade oxidativa dos neutrófilos. Veterinária Notícias, 29, 12-26.

Sowande, O. S. \& Sobola, O. S. 2008. Body measurements of West African Dwarf sheep as parameters for estimation of live weight. Tropical Animal Health and Production, 40, 433-439.

Tixier-Boichard, M., Ayalew, W. \& Jianlin, H. 2008. Inventory, characterization and monitoring. Animal Genetic Resources Information, 42, 29-44.

Wildblood, L. A., Kerr, K., Clark, D. A. S., Cameron, A., Turner, D. G. \& Jones, D. G. 2005. Production of eosinophil chemoattractant activity by ovine gastrointestinal nematodes. Veterinary Immunology and Immunopathology, 107, 5765.

Zepeda, H., Vázquez, A. C. S., Serrano, E. R., García, M. H., Cruz, B., Bermejo, J. V. D. \& Guerra, F. 2002. Estúdio de los recursos genéticos de México: características morfológicas y morfoestructurales de los caprinos nativos de Puebla. Archivos de zootecnia, $51,8$.

License information: This is an open-access article distributed under the terms of the Creative Commons Attribution License, which permits unrestricted use, distribution, and reproduction in any medium, provided the original work is properly cited. 